\title{
Slowing resource loops in the Circular Economy: an experimentation approach in fashion retail
}

\author{
Nancy Bocken ${ }^{1,2,3^{*}}$, Karen Miller ${ }^{1}$, Ilka Weissbrod ${ }^{4}$, Maria Holgado ${ }^{1}$, Steve Evans ${ }^{1}$ \\ ${ }^{1}$ University of Cambridge, Department of Engineering, Institute for Manufacturing, 17 Charles Babbage Road, Cambridge \\ CB3 OFS, United Kingdom. \\ 2 Lund University, IIIEE, Tegnérsplatsen 4, 22350 Lund, Sweden \\ 3 TU Delft, Industrial Design Engineering, Landbergstraat 15, 2628 CE Delft, The Netherlands \\ ${ }^{4}$ Imperial College London, Centre for Environmental Policy, Faculty of Natural Sciences, London SW7 1NA, United \\ Kingdom \\ *nmpb2@cam.ac.uk
}

\begin{abstract}
The Circular Economy is viewed as an important driver for resolving resource issues and tackling sustainability issues more broadly. The fashion industry operates in a largely linear way and suffers from various environmental, societal and economic challenges. In a Circular Economy, first and foremost, products need to be retained at the highest level, thus slowing resource loops. Slowing resource loops goes against current fast fashion trends and therefore appears the most difficult approach to pursue. This paper investigates how a large established retailer aims to slow resource loops as part of a broader project targeted to significantly reduce textile waste to landfill. The retailer collaborated with a university partner to pursue circular business model experiments. This paper reports on the approach for a slowing resource loops experiment around building sewing capabilities. Suggestions for future research and practice on circular business model experimentation are included.
\end{abstract}

\section{Background}

The Circular Economy has been regarded as a key driver for sustainability transitions, the concept being promoted by policy-makers, business and academia [1]. It is an "economic system that replaces the "end-oflife' concept with reducing, [or] alternatively reusing, recycling and recovering materials in production/distribution and consumption processes" to accomplish sustainable development [2]. While there are many ways to depict the circular economy [3] we summarise the main strategies as closing, slowing and narrowing resource loops [4, 1]. Slowing loops refers to the design of long-life goods and product-life extension - the use period of products is extended and/or intensified, resulting in a slowdown of the flow of resources as it reduces the total need for products [4]. Closing loops is about recycling or closing the loop post (re-)use and production, resulting in a circular flow of resources and narrowing loops is about efficiencies in manufacturing and using less material per product, for example through lightweighting products [4]. In a future circular economy, materials such as textiles should be maintained at the highest level as long as possible, through business models that focus on reuse and strategies such as maintenance and repair, service and warrantees to encourage reuse over time [5]. This requires a substantial shift in production and consumption patterns and in the role of business in society [6].

The fashion industry in particular has been signified as predominantly linear, producing vast and growing amounts of waste every year [3]. Clothing production has doubled in the last 15 years, whereas clothing utilisation (the number of times a garment is worn) is estimated to have has decreased by 36\% [7]. Textiles and clothing have significant environment and social impact across the life cycle, ranging from carbon emissions to water, and waste, toxic materials and health and labour issues [8]. WWF [9] estimated that 2.4\% of the world's crop land is planted with cotton and that it accounts for $24 \%$ and $11 \%$ of the global sales of 
insecticide and pesticides respectively. Unsafe use of these chemicals has severe health impacts on workers in the field and on ecosystems [9]. The annual increase in textile use shows that slowing consumption would be a thorny topic to tackle, but it can have a significant effect as fibre production dominates clothing's product life cycle impacts [10]. An increase of $10 \%$ in second hand sales could save $3 \%$ in carbon emissions, $4 \%$ in water and $1 \%$ in waste [10]. Businesses have experimented with slower consumption or sufficiency models. For example, outdoor company Patagonia started experimenting with a zero-growth model and nonconsumerist sales approaches [11].

This paper focuses on experimenting with approaches that facilitate product life extension in a business context. Experimentation with new business models is necessary for long-term competitiveness [12] as well transitioning to sustainable and circular businesses [13]. In particular for difficult topics such as sustainable consumption and sufficiency which challenges principles of growth [11] experimentation can be beneficial. For the circular economy to become an 'environmental success', experiments to help slow resource loops are needed. This paper addresses the following question: How can companies start experimenting with slow consumption as part of their business models?

This paper reports on a large international clothing retailer case. Through a collaborative project, the company aimed to divert all clothing from landfill through business model innovations. The paper reports on a business model experiment that was part of the project. The remainder of the paper is structured as follows. First, the case study methodology is described. This is followed by a description of the main project outcomes. The paper then includes a discussion and conclusions.

\section{Case study approach}

This research explores how companies start experimenting with slow consumption as part of their business models through a case study with a large international retailer. The focus is one highlighting some of the key decision-making during the process by showing the evolvement of ideas using product documentation.

The case study covers a 2.5-year collaborative research project (2014-2016) part funded by Innovate UK, between a university and an established international clothing retailer. The project aim was to eliminate clothing waste being disposed to landfill, using a circular value chain and business model approach for the retailer. The project aimed to identify pathways to transform the current linear business model to a more circular one, through business model and supply chain innovation facilitating recovery and reuse of clothing, using experiments. Slowing resource loops became the priority of the project with a focus on waste prevention through clothing reuse. Second, the focus was on how to encourage recycling, thus closing loops. Finally, another project objective was to learn and develop a circular business model experimentation capability for future innovation endeavours.

In the project, an experimentation approach was gradually adopted, building on Lean Startup principles [14, 15] characterised by rapid learning iterations in a low cost and resource manner $[14,16]$. This approach entails quick iterations of generating ideas, building 'prototypes' (e.g. mock websites or paper versions of the business models [17], measuring impacts, and learning and reiterating). See Figure 1 for a depiction of this iterative approach. Short learning cycles through continuous customer testing is key to the Lean Start-up approach $[14,16]$ and has long been acknowledged as trait of companies that are able to adapt to changes in the operating environment [12]. The Lean Startup approach was initially developed for startups but is now also being applied to large established businesses $[14,16]$. 


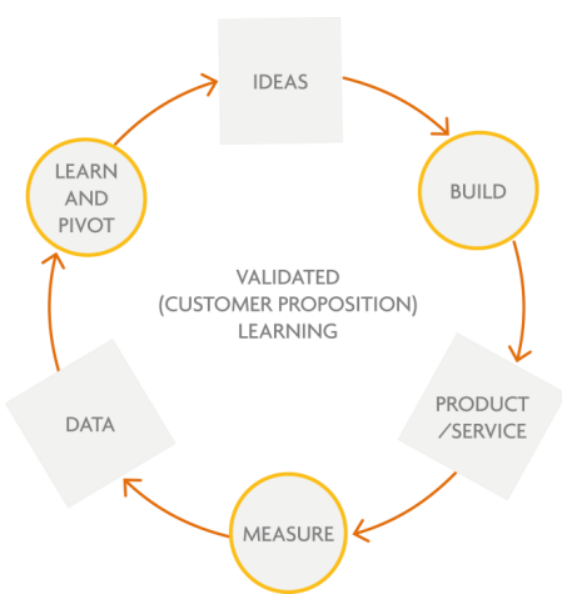

Figure 1. Lean startup approach $[13,14,15]$

\section{Case study: Slow consumption experimentation at retail}

The project sought to develop an intentional and stepwise process, however, in reality it was mainly emergent and extremely iterative [18] due to the turbulent nature of the fashion industry and ongoing business pressures from emerging competition, downward pressures on prices and increasing stakeholder pressures [20]. Within the project four different overall stages of the circular business model experimentation process could however be identified: ideating, clustering, experimenting and refining [18]. Whereas the ideation and clustering phases took about 2-3 months each, experimentation was the main part of the project, taking about 10 months. The ideating and clustering phases led to five idea clusters in total: four focused on extending and retaining the useful life of clothes, and one focused on recycling used clothing [18]. The focus in this paper is on the "care and repair" cluster of which "sewing experiments" were a key subtheme. Sewing could help build awareness about clothing reuse and develop skills and interests around clothing repair and care. Several other experiments were conducted for the other four clusters (as well as more for the care and repair cluster), but are beyond the scope of this study. We report on an experiment that focused on 'sewing' and how the ideas evolved in the project into an experiment.

During each stage (ideating, clustering, experimenting, refining), multiple activities reoccurred. So, although the process was highly iterative and emergent, some recurring activities were identified [18]:

1. Gather market, customer and environmental data and prepare analysis (desk research)

2. Conduct workshops with ideation and engagement and consensus purposes (involving various stakeholders in and outside the business, such as senior staff, those who took part in experiments, and NGOs and start-ups)

3. Generate new questions for further analysis (involving various stakeholders)

4. Run experiment and collect further data

To sketch the landscape of the care \& repair cluster the template in Table 1 was developed. It was used to populate all the idea clusters. These templates were a collection of the considerations taken in the project and were developed in conjunction with key stakeholders in the business (senior management in innovation and fashion). These fitted into the 'desk research' type of study to explore the market, environmental benefits and customer traction. It should be noted that even before the initial ideation workshops, desk research was done to understand the (recycling) technologies in the fashion industry, potential environmental initiatives, new startups, market trends etc. This gathering of supporting data was ongoing throughout the project. 
Table 1. Initial idea template to sketch the landscape for the care \& repair experiments

\begin{tabular}{|c|c|}
\hline 1. What is the 'idea cluster'? & Care \& Repair \\
\hline 2. Why is this important? & $\begin{array}{l}\text { Work back from 'ideal' business model } \\
\text { • Slowing loops }\end{array}$ \\
\hline 3. What categories might it apply to? & $\begin{array}{l}\text { It is already happening here: } \\
\text { - } \quad \text { Footwear } \\
\text { Things that easily break/ need repairing: } \\
\text { - Buttons } \\
\text { - Zips } \\
\text { - Hems } \\
\text { - Patches (knee and elbow) } \\
\text { - Moths }\end{array}$ \\
\hline Size of the category? & TBC (market study) \\
\hline $\begin{array}{l}\text { 4. What are others doing? Who are } \\
\text { competitors? }\end{array}$ & - $\quad$ Nudie Jeans, Mud Jeans, Patagonia etc. \\
\hline $\begin{array}{l}\text { 5. What opportunities could there be for } \\
\text { the company? What value does it create } \\
\text { for the company? What benefit does it } \\
\text { create for the customer? }\end{array}$ & $\begin{array}{l}\text { Company value creation } \\
\text { - } \quad \text { Premium branding \& reputation for products } \\
\text { with long warrantee } \\
\text { - } \quad \text { Footfall \& speculative purchasing (e.g. coffees } \\
\text { in coffee/ tea shops) } \\
\text { - } \quad \text { Sell the repair service } \\
\text { - } \quad \text { Payside and outside warranty difference? } \\
\text { service with designers }\end{array}$ \\
\hline $\begin{array}{l}\text { 6. What are the challenges we already we } \\
\text { already know about? }\end{array}$ & $\begin{array}{l}\text { - Designed for easy repair or disassembly } \\
\text { - How to make money? } \\
\text { - } \quad \text { People have lost the skills and awareness } \\
\text { - } \text { Cheap 'disposable' clothing } \\
\text { - } \quad \text { Repair technologies we are not aware of? }\end{array}$ \\
\hline $\begin{array}{l}\text { 7. What are the challenges we want to test } \\
\text { in the pilots? }\end{array}$ & Tbc (workshop approach) \\
\hline 8. Potential partners? & $\begin{array}{ll}\text { - } & \text { Designers (for refurbishing/ embellishing) } \\
\text { - } & \text { Dry-cleaners \& shoe repairers } \\
\text { - } & \text { Network of tailors (wine masters) } \\
\text { - } & \text { Great British/ Sewing Bee } \\
\end{array}$ \\
\hline 9. Adjacent industries to learn from? & $\begin{array}{ll}\text { - } & \text { Engineering maintenance } \\
\text { - } & \text { Car maintenance (annual wardrobe MOT) } \\
\text { - } & \text { Build-a-bear }\end{array}$ \\
\hline
\end{tabular}

Multiple meetings, workshops and further analysis took place. The Lean Startup idea $[14,16]$ was introduced more formally into the project after the first workshops. This led to a focus on developing experiments with key hypotheses and learning to test. While multiple types of templates were used [18], one of the key project templates can be found in Figure 2, building on the experiment templates developed by Osterwalder et al. [19]. This experiment card can be used by businesses to 'get on the same page' before undertaking experiments: understand the core issues, the hypotheses to test and what to measure. The experiment card in Figure 2 was populated in preparation for rolling out key experiments around this theme. As can be seen from Figure 2, the first experiment aimed to test demand for sewing lessons online, before setting up an experiment in the retail shop. The population of such cards also consisted of individual work, followed by meetings with the whole project team. 
While this template (as well as others) was important for engagement and consensus purposes, amongst the project team stakeholders and key stakeholders in the business (i.e., senior management and those supporting the roll out of experiments), the selection of an actual experiment was more opportunistic. One of the industry team members identified an opportunity to become engaged in a 'sustainability week' and set up sewing experiments within a shop as part of this event. This allowed the experiment to take place out in the open but in fact also 'under the radar' as part of a normal event. The experiment could build on key interests and skills of one of the project team members (highly involved in the sewing community) who understood the needs and opportunities.

Metrics were developed similar to Figure 2 (e.g., whether there was a demand, which types of lessons, demographics), and observation as well as informal conversations took place to gather 'evidence'. Observation sheets were created by the 'observers' (who in fact participated themselves, or were supporting the coordination of the event) which were then merged into one 'data document'.

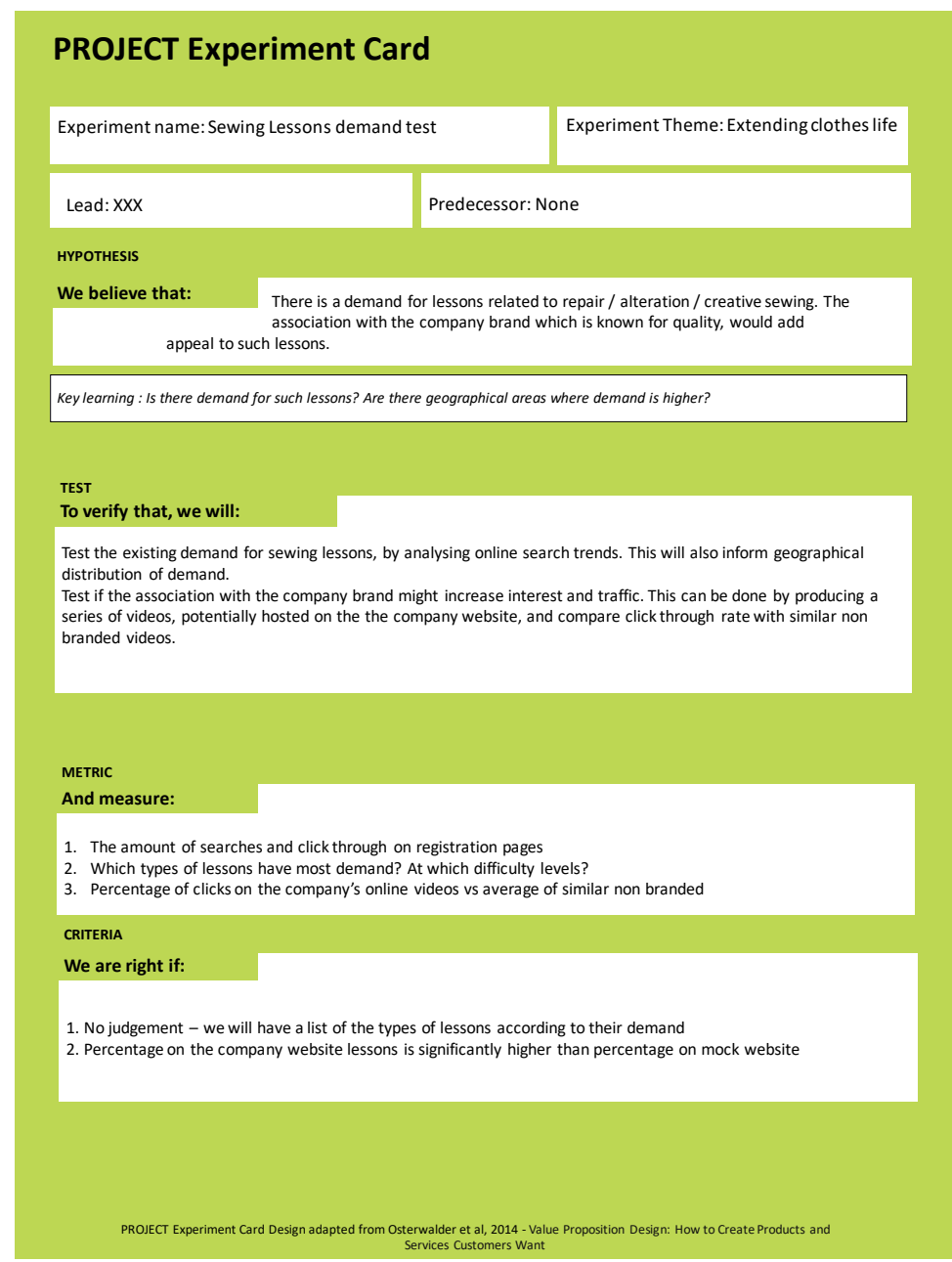

Fig. 2. Experiment cards used during the project for the Care and Repair theme, later themed "Extending clothes life".

Building on $[18,19]$.

Interestingly, eventual decision-making about success or failure of the experiments happened more intuitively and based on different criteria than those initially set out by the project team. This occurred as a result of the retailer project team members having less time than planned to review and revisit the experimentation documents. Senior Management team members also foreshortened the experimentation after being briefed on the experiments, accelerating the decision-making process. The need to make fast decisions and follow up 
with action may have been the result of the fast-paced nature of the fashion industry, but there was also significant enthusiasm within the steering group to be able to try new propositions for the business in the research project's context.

The following reflections and lessons can be learned from the process of setting up a sewing experiment in the retail shop:

1. The process of setting up experiments emerged through phases of analysis and gathering data in project templates, ideation and implementation. This process was iterative, involving individual data analysis, multiple meetings within the project team followed by engagement with key stakeholders in the business, and finally implementation in a shop. Because of the nature of 'large business', and the need to set up experiments in a turbulent business environment, it was felt that this process took much longer than it would have in a startup environment.

2. Initial hypotheses were formulated but eventually all types of learning were tracked. Similar to the broader 'metrics' in Table 1, the broader context and business benefits of doing a sewing experience in a large retail shop were evaluated. For example, does it fit with the brand? Does it create new opportunities for the company? The observations and conversations with participants as well as interest from shoppers passing-by, indicated a real engagement with sewing, repairing and looking after clothes and the environment. Another reason for the felt need to track all kinds of learning may originate from the fact that the company could 'finally' test a novel business model direction out in the open.

3. Decision-making became intuitive, rather than formalised. Specific hypotheses were formulated for the sewing experiments. However, the shop manager who was not part of the project team, became so enthusiastic because of the success of the event (customer traction, positive responses from the public), that it resulted in the retail shop running more such events. This had further spill-over effects with more the events in other parts of the country. At the time of writing, nine further 'sewing events' had taken place in retail shops. In large business contexts decision-making may be more complex and dispersed [20], and ideas may be accepted or rejected unexpectedly. This may be positive, when an experiment has failed the hypotheses test, but gets embedded because of other reasons (e.g. footfall in store; building the brand). It was found that project documentation and data analysis do support engagement and consensus making about which experiments to pursue, but decisions may be made more intuitively and in unexpected ways.

4. Environmental impact improvement is difficult to derive from single experiments. Businesses may have 'environmental value propositions' in mind when designing the business model [21] and indeed an environmental intent was described for each of the ideas (Table 1). Nevertheless, the actual impact of business model innovation, in particular those aimed at longer product life times and slowing resource loops, may only be felt over a longer period of time. Hence, it is important to keep track of progress against such goals (e.g. prevented waste, recycling rates etc).

5. Slow consumption is (evidently) a challenging topic in fast fashion. 'Slow consumption' in a highly competitive environment with downward pressures on prices is a difficult concept in particular with senior management who are under pressure to deliver to short-term sales targets. Whereas in the project, companies like Patagonia were often mentioned as examples of sufficiency, it was felt that it was difficult for the company to undergo such a radical transformation to a more premium-priced business model, which in theory could justify slower flows of fashion. It should be noted that 'slow consumption' was also absent as a strategy from the recent Ellen MacArthur Foundation [3] report on circular economy for the textiles industry, indicating it remains a demanding topic. Nevertheless, new models would need to be explored to slow resource use (e.g. more premium, charging for services etc.).

6. Experimentation can accelerate new sustainable business activity. As an overall reflection of the process, the project generated new activity and adoption of an innovation and learning approach based on experimentation: in interviews which took place after concluding the project it was noted by the project 
coordinator that 'expectations had been surpassed' as typically 'it is difficult to make stuff happen in a large business' [18]. New propositions were tested and rolled out, and others were trailled with niche customers. Success was thus defined as the new experimentation approach being adopted and new business activity and transformation taking place in the business.

\section{Discussion and conclusions}

This paper explored the following question by means of a company case of an international fashion retailer: How can companies start experimenting with slow consumption as part of their business models?

The case study presented an example of the emergence of an experiment to test the interest in sewing lessons in a shop, with the ultimate goal to make people more environmentally conscious about clothing (re)use and (re)building skills and interests in repair and care for clothes. The process to develop experiments was described, and included an analysis phase (e.g. market, customer and environmental data), workshop phase for ideation, engagement and consensus, generating new questions for analysis and running experiments and collecting further data. Templates were included that could support experimentation processes in other large business contexts. It was found that:

1. The process of setting up experiments emerged through phases of analysis and gathering data in project templates, ideation and implementation.

2. Initial hypotheses were formulated but eventually all types of learning were tracked.

3. Decision-making became intuitive, rather than formalised.

4. Environmental impact improvement is difficult to derive from single experiments.

5. Slow consumption is (evidently) a challenging topic in fast fashion.

6. Experimentation can accelerate new sustainable business activity.

This study shows that the process of experimentation for circularity and sustainability in a large business context remains a promising avenue for future research as it can spark new activities and practices, which are at the heart of sustainability transitions [22]. While decision-making may seem 'rigid' and formalised in large business, it was found that the tangible real-life context evidence that experiments bring may help accelerate and fast-track decision-making. Important other research areas relate to tracking environmental impact improvements in sustainable and circular business model innovation; identifying ways to slow resource loops; and developing slow consumption into viable business model strategies.

\section{Acknowledgements}

This work was supported by the EPSRC Centre for Innovative Manufacturing in Industrial Sustainability (Reference EP/I033351/1); the Innovate UK competition 'Supply Chain Innovation towards a Circular Economy' (IUK Ref 101902); and Climate-KIC, the public-private partnership created by the European Institute of Innovation and Technology (Regulation (EU) No 1292/2013).

\section{References}

[1] Geissdoerfer, M., Savaget, P., Bocken, N., Hultink, E.: The Circular Economy - a new sustainability paradigm? J. Clean. Prod., $143,757-768$ (2017).

[2] Blomsma, F., Brennan, G.The Emergence of Circular Economy: A New Framing Around Prolonging Resource Productivity J.Ind. Ecol., 21, 603-614. (2017)

[3] Kirchherr, J., Reike, D., Hekkert, M. Conceptualizing the circular economy: An analysis of 114 definitions. Res., Conserv. Recycl., 127, 221-232 (2017). 
[4] Bocken, N.M.P., de Pauw, I., van der Grinten, B., Bakker, C. Product design and business model strategies for a circular economy. J. Industr. Prod. Engin., 32 (1), 67-81. (2016)

[5] Achterberg, E., Hinfelaar, J., Bocken, N.M.P. : Master circular business models with the Value Hill. White paper, (2016). [6] Merli, R., Preziosi, M., Acampora, A. How do scholars approach the circular economy? A systematic literature review. J. Clean. Prod. 178, 703-722 (2018).

[7] Ellen MacArthur Foundation (EMF), A new textiles economy: Redesigning fashion's future. (2017)

[8] Allwood, J. M., Laursen, S. E., Russell, S. N., de Rodríguez, C. M., \& Bocken, N. M. P.: An approach to scenario analysis of the sustainability of an industrial sector applied to clothing and textiles in the UK. J. Clean. Prod., 16(12), 1234-1246. (2008).

[9] WWF. Cotton Farming. Cotton: a water wasting crop. (2017).

[10] WRAP. Valuing our clothes. WRAP UK (2017).

[11] Bocken, N., Short, S. Towards a sufficiency-driven business model: Experiences and opportunities. Environ. Innov. Soc. Trans., 18, (41-61) (2016).

[12] Chesbrough, H.: Business model innovation: opportunities and barriers. Long Rang. Plann.., 43 (2), $354-363$ (2010).

[13] Weissbrod, I., Bocken, N. : Developing sustainable business experimentation capability - a case study. J. Clean Prod., 142 (4). 2663-2676. (2017).

[14] Ries, E.: The lean startup. Penguin Books, London (2011)

[15] Blank, S.: The Four Steps to the Epiphany: Successful Strategies for Products That Win. K\&S Ranch Publishing, San Francisco, USA.(2013)

[16] Ries, E. The startup way. Penguin Random House UK, Milton Keynes UK. (2017).

[17] Schuit, C, Baldassare, B., Bocken, N.: Sustainable business model experimentation practices: evidence from four start-ups. Product Lifetimes and the Environment (PLATE), 8-10 November (2017).

[18] Bocken, N.M.P., Weissbrod, I., Miller, K., Holgado, M., Evans, S.: Business Model Experimentation for Circularity: Driving sustainability in a large international clothing retailer. 1-2. Economics and policy of energy and the environment (ISSN 2280-7659, ISSNe 2280-7667), (2017).

[19] Osterwalder, A., Pigneur, Y., Bernada, G., Smith, A.: Value Proposition Design. How to create products and services customers want. John Wiley \& Sons, Hoboken. (2014).

[20] Miller, K.: Visionary leadership: learning from exemplary organizations. In A. Vecchi, \& Buckley, C. (Eds.), Handbook of research on global fashion management and merchandising (pp. 1-32). IGI Global.( 2016.)

[21] Manninen, K., Koskela, S., Antikainen, R., Bocken, N., Dahlbo, H. and Aminoff, A., Do circular economy business models capture intended environmental value propositions?. J. Clean. Prod., 171, 413-422 (2018).

[22] Shove, E. Pantzar, M., Watson, M.: The Dynamics of Social Practice. Everyday Life and how it Changes. SAGE Publications Ltd, London, 208p. (2012). 